\title{
Commercializing College: An Analysis Of College Representations During Bowl Games
}

Received (in revised form): April 17, 2006

\section{Barbara F. Tobolowsky}

Barbara F. Tobolowsky is the Associate Director of the National Resource Center for The First-Year Experience and Students in Transition at the University of South, Carolina.

\section{John Wesley Lowery}

Jhon Wesley Lowery is Associate Professor in the School of Educational Studies at the Oklahoma State University and coordinates the college student affairs program. He previously served on the faculty at the University of South Carolina.

\author{
Abstract \\ College expectations play an important \\ role in students' success at an \\ institution. Braxton et al. (1994) found \\ that if expectations are met, students \\ are more likely to persist than if they \\ are unmet. One potential contributor \\ to college expectations is media \\ (Tobolowsky, 2001). Prior research \\ concludes that colleges that play in \\ bowl games experience application \\ spikes. However, there has been little \\ research on the institution-produced \\ public service announcements (PSAs) \\ that air during those games and may \\ contribute to the college expectations \\ of entering students. This study

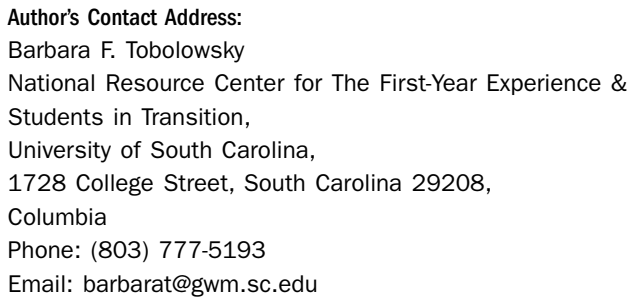

analyzes the campus PSAs in 27 bowl games over two years, 2003-2004 and 2004-2005, to better understand the college portrait in these unique media offerings.

International Journal of Educational Advancement (2006) 6, 232-242. doi:10.1057/palgrave.ijea.2150018

\section{Keywords:} media, football bowl games, college student life, representation, and advertising

\section{Introduction}

Providing access to college is a central issue for higher educators. However, access does not ensure academic success. Today, a large percentage of students who enroll in postsecondary institutions do not persist to graduation (NCES, 2004-156). Prior research has found that many variables (e.g., motivation, support, college information, and first-generation 
status) impact a student's ability to succeed in college (Terenzini et al., 1996). Another potential reason for students' lack of persistence is that their college experience does not match their expectations (Braxton et al., 1995; Gerdes \& Mallinckrodt, 1994). Thus, it is important to gain some understanding of the students' expectations and those information sources that influence them.

Most educational research focuses on more traditional variables that contribute to the development of college expectations (e.g., orientation, campus tours, family educational backgrounds) (Kuh, 1991; Kuh et al., 2005). A less understood information source that influences college expectations is the representation of college on prime-time television (Tobolowsky, 2001). Tobolowsky found that the depiction of college life in prime-time series contributed to tenth-grade Latinas' expectations of the experience. Further, Toma and Cross (1998) suggested that a key information source is athletics. They go on to note that "Spectator sports are the most important medium to get the word out about the school-sports can sell a lot of things for the university" (p. 204). Specifically, they found that most institutions with championship football teams saw application spikes immediately after a winning season and for at least three years after their win. In fact, colleges with winning teams get a considerable amount of exposure on television. Toma (2003) confirmed that sports such as college football can contribute greatly to an institution's national visibility through televised games.

The visibility is not limited to the game itself. The competing institutions produce short promotional pieces that are aired at the network's discretion during the games. These public service announcements (PSAs) are golden opportunities for institutions to reach a wide audience and project a desired image. In contrast to these institutioncreated spots, other media sources may not present as positive (i.e., wholesome) a representation of college life. Unconsciously, they may contribute to a more unflattering perception of college. For example, watching rampant alcohol abuse in National Lampoon's Animal House (1978) or reading about college faculty's liberal bias (Chu, 2005) in newsmagazines may create negative expectations of the college experience in some viewers (Tobolowsky, 2001). However, these campus-produced spots provide institutions the opportunity to present positive messages that can address any perceived negative views.

Clearly, these television ads are not the only way colleges inform the public about their campuses.

Institutional websites and admissions material routinely present a positive college portrait, but in those cases only individuals seeking information are exposed to the messages. The PSAs aired during bowl games are unique, because they automatically reach a wider, and most likely, more diverse audience than the more traditional campus publications. For example, ESPN had, on average, 1.7 million households watching college football games during the 2005 season (www. mediaweek.com). That number jumps dramatically during the bowl games; for instance, ABC garnered a 13.7 rating (over 13 million viewers) for the 2005 championship game at the Orange Bowl ${ }^{1}$ (www.bcsfootball.org/ 
index.cfm? page=tvratings). Therefore, these spots have the potential to have an impact on the attitudes of a very large number of people. Thus, televised college sports and the college-produced ads provide an important window for viewers into college life, in general, and specific institutions, in particular.

Although studies have explored the nature of college advertising (e.g., Anderson, 1994; Hite and Yearwood, 2001; Jugenheimer, 1995; Kittle, 2000; Klassen, 2000), little research has been done regarding the messages conveyed in and by televised bowl games. More specifically, almost no research has been conducted on the 30-second to 1-minute PSAs aired during these games. Although these ads represent a very small portion of the total broadcast time, they may influence the college expectations of a large number of viewers. Before we are able to determine the potential impact of these spots, we must get a better understanding of the college portrait presented in them.

Thus, this study asks:

1. What are the messages about college life as represented in these commercials?

2. Is there a consistency to the messages conveyed in these ads? Which themes are consistent and which reflect unique views of college life?

\section{Theoretical Framework}

The goal of this study is to determine the extent and consistency of the college representation depicted in these self-produced profiles of college life. For the purposes of this study, cultivation theory provides the lens through which to view these images. This media theory posits that consistent and persistent television images impact viewers' conception of the world (Weimann, 2000). It contends that individuals who are heavy television viewers have been found to be more likely to incorporate televisual views into their own selfconstructed perspectives of life, relationships, and the world than people who rarely watch this medium. Thus, the pervasive messages in these ads may impact the college perceptions of a wide range of viewers who watch bowl games.

\section{Method}

Before being able to determine the influence of these ads, it is necessary to understand the messages themselves. Between mid-December, beginning with the New Orleans Bowl and concluding with the Bowl Championship Series National Championship game, there are 28 postseason NCAA Division IA bowl games played each season. This research focused on the bowl games played between December 31 and January 4 for two years, the 20032004 and 2004-2005 bowl season. The games played from New Year's Eve through the end of the bowl season have traditionally been considered the more prestigious, which is why these were the focus of this study. In total, the researchers taped 27 football games played by 54 institutions over two years (i.e., 15 football bowl games played from December 31, 2003 to January 4, 2004 and 12 games played between December 31, 2004 to January 4, 2005). Across these two bowl seasons, 16 institutions were involved in bowls both years. Further, of those 16 
institutions, six of them showed the same commercial both years for a total of 48 different institutional commercials. See Table 1 for a complete list of institutions and bowl games included in the study.

The researchers reviewed the institutional spots independently noting

Table 1: Institutions of Higher Education and 2003-2004 and 2004-2005 Bowl Games

\begin{tabular}{|c|c|c|}
\hline Institution of Higher Education & 2003-2004 Bowl Game & 2004-2005 Bowl Game \\
\hline Arizona State University & & Vitalis Sun Bowl \\
\hline Auburn University & Gaylord Hotels Music City Bowl & Nokia Sugar Bowl \\
\hline Boise State University & & Autozone Liberty Bowl \\
\hline Boston College & Diamond Walnut San Francisco Bowl & \\
\hline Clemson University & Chick-fil-A Peach Bowl & \\
\hline Colorado State University & Diamond Walnut San Francisco Bowl & \\
\hline Florida State University ${ }^{\mathrm{a}}$ & FedEx Orange Bowl & Toyota Gator Bowl \\
\hline Georgia Tech University & Humanitarian Bowl & \\
\hline Kansas State University & Tostitos Fiesta Bowl & \\
\hline Louisiana State University & Nokia Sugar Bowl & Capital One Bowl \\
\hline Ohio State University & Tostitos Fiesta Bowl & \\
\hline Oklahoma State University & SBC Cotton Bowl & \\
\hline Purdue University ${ }^{\mathrm{a}}$ & Capital One Bowl & Vitalis Sun Bowl \\
\hline Texas A\&M University & & SBC Cotton Bowl \\
\hline University of Alabama & & Gaylord Hotels Music City Bowl \\
\hline University of Arkansas & MainStay Independence Bowl & \\
\hline University of Florida & Outback Bowl & Chick-fil-A Peach Bowl \\
\hline University of Georgia & Capital One Bowl & Outback Bowl \\
\hline University of Iowa $^{\mathrm{a}}$ & Outback Bowl & Capital One Bowl \\
\hline University of Louisville & & Autozone Liberty Bowl \\
\hline University of Maryland & Toyota Gator Bowl & \\
\hline University of Miami ${ }^{\mathrm{a}}$ & FedEx Orange Bowl & Chick-fil-A Peach Bowl \\
\hline University of Michigan & Rose Bowl & Rose Bowl \\
\hline University of Minnesota ${ }^{a}$ & Wells Fargo Sun Bowl & Gaylord Hotels Music City Bowl \\
\hline University of Mississippi & SBC Cotton Bowl & \\
\hline University of Missouri & MainStay Independence Bowl & \\
\hline University of Oklahoma & Nokia Sugar Bowl & SBC Cotton Bowl \\
\hline University of Oregon & Wells Fargo Sun Bowl & \\
\hline University of Pittsburgh & & Tostitos Fiesta Bowl \\
\hline University of Southern California & Rose Bowl & FedEx Orange Bowl \\
\hline University of Southern Mississippi & AXA Liberty Bowl & \\
\hline University of Tennessee & Chick-fil-A Peach Bowl & SBC Cotton Bowl \\
\hline University of Texas & & Rose Bowl \\
\hline University of Tulsa & Humanitarian Bowl & \\
\hline University of Utah ${ }^{\mathrm{a}}$ & AXA Liberty Bowl & Tostitos Fiesta Bowl \\
\hline University of Wisconsin & Gaylord Hotels Music City Bowl & Outback Bowl \\
\hline Virginia Tech & & Nokia Sugar Bowl \\
\hline West Virginia University & Toyota Gator Bowl & Toyota Gator Bowl \\
\hline
\end{tabular}

aAlthough this institution completed in bowl games in the 2003-2004 and 2004-2005 bowl season, the same commercial was broadcast both years. 
a range of production elements (e.g., dialogue, visuals, camera movements, music). After analyzing the segments individually, the researchers met to discuss their findings to guarantee interrater reliability. With this insight, they returned to their written records and the videotaped material to review the PSAs again. At this point, as with other qualitative methods, themes and concepts emerged regarding the images. With the use of analytic memos and the constant comparative method, the list of themes was refined.

\section{Commercializing College}

There was a surprising consistency between the ads regarding their representation of college. The primary themes that emerged were that college life is innocent, honors tradition and history, and embraces the future. Although many of the ideas were repeated in the ads, there were some notable exceptions. The following sections will discuss these similarities and inconsistencies in more detail.

\section{The Age of Innocence}

The overriding image in all the ads is that college is a time of innocence. The common popular images of drunk and irreverent students and unsupportive faculty more commonly seen on television (e.g., Felicity, Buffy: The Vampire Slayer) are quickly replaced with images of wholesome students enjoying traditional, idyllic college experiences (e.g., working happily in study groups on bucolic grounds, performing or attending performances, attending packed sporting events and displaying great enthusiasm). Campuses are clean, safe, and landscaped. Students enjoy academic pursuits and show school spirit at school-sponsored sporting events and dance and musical performances. Students are happy studying with a group of students or walking on a campus path. There is no evidence of political controversies, financial challenges for the individual or the campus, illegal substances, depression, or dissatisfaction. This college portrait is almost identical to the traditional college life portrayed decades ago (only clothing and hair styles may reflect a more recent time).

\section{Honoring the past}

Specifically, the two most consistent themes that emerged from the analysis were "honoring the past" and "shaping the future." The tie to the past was illustrated in several ways. There were literal or direct associations (i.e., the school motto), symbolic associations (i.e., architecture), and emblematic links (i.e., rankings, history, and curricular and cocurricular offerings).

The past is equivalent to notions of tradition and quality. One way colleges reflected their tie to the past was in their identification. For example, every ad ended with the school name, their logo or crest, and their motto. Crests, which were originally placed on shields in the eleventh and twelveth centuries, link US colleges to the more historical (i.e., old and high quality) European institutions from which they were patterned. Often, schools in these ads would also note the founding date to reflect their histories (e.g., University of Georgia, 1785; University of Southern California, 1880; University of Florida, 1853). In addition, some mottos specifically focused on the past 
and tradition (i.e., Southern California's "... honoring the past") while others suggested a tradition of excellence (i.e., West Virginia University's "where greatness is learned," Louisiana State University's "A great game plan on and off the field").

Another way schools trumpeted their ties to tradition was symbolically through their architecture. Many of these colleges highlighted a tower, clock tower, or columns to reflect their tie to history (e.g., Louisiana State University, University of Alabama, University of Wisconsin). In these ads, the architectural past provided a link to quality and stability. Even some newer schools showed towers, which suggests an attempt to link their institution and the concept of quality that institutions with a longer history claimed (e.g., Oklahoma State, Kansas State). Other schools used photos to convey their sense of tradition. For example, the University of Florida showed students from the turn of the century to the present day to illustrate their long and rich history. Texas A\&M talked specifically about their "timeless tradition" and that is was a "place of rich history" while showing black and white historical photos of campus.

An emblematic tie to quality was illustrated through references to rankings (e.g., Maryland, Kansas State), stellar faculty (e.g., Maryland, Boise State), and student scholars (e.g., students with Roosevelt, Rhodes, Marshall, Truman, Udall, and Goldwater scholarships were mentioned in ads for Georgia, Oklahoma State, and Mississippi) as well. The University of Maryland listed that it is 17 th among national public institutions with the University of Mississippi ("a great American public university") and the University of Oklahoma ("a flagship of excellence") also positioning themselves as highly regarded public institutions. Other institutions made linkages to Ivy League campuses (e.g., University of Georgia cuts from a still with the names of Harvard, Yale, and Brown to the University of Georgia crest), so they make connections to institutions known for their tradition and quality. Oklahoma State offered a few unique statistics. In addition to listing the fact that they had Rhodes, Truman, and Goldwater scholars and 1,500 valedictorians, they also stated that they had "America's Greatest Homecoming" and the "World's Largest Student Union.” Thus, colleges proudly share any honor they may have earned that makes them stand out from other campuses.

Just as the institutions expressed their ties to the past through their architecture or rankings, a number of institutions made that linkage by discussing their curricular and cocurricular efforts. Boston College discussed their focus on the Western canon of Aquinas, Descartes, and Dostoyevsky. These traditional works represent a Eurocentric historical perspective of the ideal liberal arts education. Other schools focused on the range of cultural events at their institutions from classical musical concerts (i.e., Colorado State, Miami, Tennessee, Kansas State, and LSU) to dance (i.e., Utah, Colorado State, Iowa, West Virginia, and Oklahoma), and art (i.e., Oklahoma).

\section{Embracing the Future}

Typically, institutions mentioned the past and the future. That link was 
evident in several of the colleges' taglines, which conveyed the sense of honoring tradition, but preparing students for the future, such as the University of Florida, which ended their PSA with the words "Honoring the past, shaping the future" and Southern California which proclaimed their institution has been "inventing the future and honoring the past since 1880." Other schools did not mention the past, but focused squarely on the future in tag lines like "Forward... Thinking" (Wisconsin), "University of the 21 st century" (Southern California 2003/04), and "Imagine the Possibilities" (Pittsburgh). Interestingly, just as some schools offered the date of their founding to provide a link to history and tradition, most of the institutions included their web address to show they are not solely looking to the past.

There were other futuristic associations evident in the ad content. Even though US manned space travel dates back to the early 1960 s, some institutions specifically linked themselves to NASA and space to reflect their tradition of pursuing cutting-edge technologies (i.e., Neil Armstrong was a graduate of USC, the crew of Apollo 15 were all University of Michigan alumni). However, other schools showed space in their spots to make that symbolic connection to the future. In the Arizona State spot, the camera moved from the city skyline to Mars and back to "your own backyard," reflecting the vast area that students can explore on that campusfrom important discoveries at home to the galaxy and beyond. These images of space played a similar role as the columns and towers, which represented a history of tradition and quality; but this time that tradition is of futuristic exploration or more simplistically (or symbolically), the future.

One of the most common visuals in all the spots was the science lab to suggest the modern thrust of the institution. Frequently, female students in lab coats and protective glasses were shown. Thus, the institutions were not just making discoveries, they were so cutting edge that women were leading the charge. This image of exploration in space or in labs was a primary element to this futuristic perspective. The Arizona State ad discussed developing vaccines, while the University of Louisville declared their campus was "an incubator of ideas," and the University of Minnesota makes "Big Time Discoveries." The University of Tennessee's spot (2004-05) focused on a special program where students developed a taillight apparatus that will make our roads safer. Although this ad was unique because an invention was the sole focus of the spot, it was very common for colleges to mention in passing some significant scientific discovery that someone on their campus made (e.g., West Virginia mentioned microchip sensors that were used to build a "smart" bridge, Florida State had footage of a "new generation of ship" and "better hurricane forecasting").

Just as the curricula and cocurricular offerings revealed a traditional bent at some schools, a wide range of offerings tended to suggest a more modern institution. For example, the 2003-04 USC spot listed a multitude of fields including gerontology, humanities, communications, policy analysis, business, cinema-television, international development, dance, and medicine. The scope of modern and 
traditional areas of study supports the notion that they are more futureoriented than other institutions that focus only on traditional fare. Sometimes the cultural offerings showcased were contemporary performances (e.g., Miami showed both classical musical performances and contemporary ones). Thus, the cocurricular and curricular representations may reflect a traditional and/or modern disposition depending on what is depicted.

Finally, student diversity was conveyed to some degree by many of the schools in their ads. Although some institutions showed a number of students from different ethnic backgrounds (e.g., Arkansas, Florida, Tulsa, Mississippi), a few schools showed less diversity with one to two (e.g., Minnesota) or no students of color (e.g., Utah, Boston College). A predominantly white institution, The University of Alabama, singled out an African-American female student as the first of several students talking about what their career goals are, suggesting that even this historically white campus is now becoming more diverse.

The notion of diversity was evident in the representation of faculty as well. However, often the focus was on gender diversity, rather than ethnic or racial diversity. In the Minnesota and Ohio State PSAs, for instance, white female faculty were highlighted. A gender-diverse faculty reflected a more modern perspective.

Another aspect of this futuristic bent was a discussion of dreams and dreaming. Just as an institution may be an "incubator of ideas," many of these campuses chose to accentuate the idea that their campuses were places that encourage students to dream or to make their dreams reality. Different students shared their dreams in the Virginia Tech spot. (A different student spoke each line.)

I dream...

I dream of producing a film that changes people's lives for the better I dream of being an architect and a designer...

I dream of using biomechanics to invent artificial organs for transplant patients.

Ending with a card that says: Their dreams will transform our world.

West Virginia University's ad stated to "start living your dreams" at their college. The University of Wisconsin's spot said that other colleges you have to "put your dreams on hold," suggesting this is not something you have to do on their campus.

Sometimes the word "dream" was not specifically stated, but the notion was still clearly conveyed. We are told that students find their "personal best" at the University of Iowa. This is a school where students are encouraged to reach their potential. In the 2003-04 ad, USC presents itself as the school for the new thinkers and creators.

Who'll create the new museums, new treaties, new countries... Who'll make art as everyday as coffee shops...

We don't know their names yet, but we see them everyday.

The notion of transforming the world and the students was frequently mentioned in many of these spots. For example, the Arizona State spot talked 
about the campus being a place that builds futures and transforms lives. The implication is that dreaming at these schools is not idle and results in a changed world.

\section{Inconsistent Messages}

Although there was great consistency in the messages, this does not mean there were not some inconsistencies as well. The two main areas of inconsistency dealt specifically with the medium itself: contradictory words and visuals and the lack of campus depictions. Interestingly, there was, on occasion, a mismatch between word and visual. For example, achievement, opportunity, and prestigious were a few of the words listed to describe the University of Mississippi. However, the visuals did not match the written words. For achievement, they showed a fairly static shot of three women typing in a computer lab. For opportunity, there was a picture of a female student with a pith helmet on posing for a picture with what appear to be a few Asian males in military shirts. It is unclear where she is or what sort of opportunity this is. For prestigious, there were two students, we assume, weightless, bouncing around in an unidentified enclosure. In these cases, the disconnect between the pictures and words tended to confuse the message rather than reinforce it.

Purdue's spot also seemed incongruous. The words focused on how Purdue was "preparing our nation for the next revolution in technology," however the visual was a slow pan from a tree to a planted field at dawn. The connection to an agrarian economy did not match the futuristic words spoken. Another example was the spot produced by Ohio State University. In this ad, a female professor talks about the decision-making process using academic language, “...one must consider the conditional properties of an information sources' success through the use of techniques such as collaborative filtering..." What we see is a woman making a choice in a video store. Whether the spot intends to be viewed as humorous or realistic, it fails because it seems to confirm the public view that faculty are out of touch with real people and real life (Gitlin, 2000), which is hardly the view one would think the institution would like to propagate.

Additionally, the predominant visuals in the ads were scenes of the campus, the students, and faculty; however, some of the PSAs were unique because they did not show these things. The USC ad in 2003-04 was animated. There were no pictures of campus, students, or faculty. However, in the following year, they showed their mascot, the Trojan (riding all around campus) as he touted their accomplished alumni-a radical reversal in approach. The University of Maryland showed a slow-moving turtle while listing the many accomplishments of its faculty and students. Finally, as mentioned previously, the University of Tennessee's singular focus on the taillight invention was very unusual as well.

In general, most of the spots had quick cuts of campus, faculty, and students to provide an overall portrait of the campus experience. The fastpaced ads often had narration supplied by a variety of students, the college president, or a professional actor. 
These images reflect a positive portrait of college life today. The similarity in content and style reinforces the representation.

\section{Conclusion}

This study begins to look at the specifics of school-produced advertisements that reach millions of bowl game viewers. On one level, these ads may play a role in potential students' creation of expectations affecting their college choice and college success. On another level, these images may be higher education's best response to the more common negative views portrayed in other media and the potentially negative views held by a segment of society, because of their uniquely wide reach. Future research would attempt to determine the effectiveness of these ads on potential college students' and the public's perceptions of higher education.

Cultivation theory suggests that viewers of these images may well incorporate them into their view of college life, thus potential students and the viewing public may see campuses as grounded in the past while moving towards the future. They see happy students daring to dream as they reach their potential, so they can transform the world for the better. This portrait is how colleges choose to represent themselves to a wide audience. Perhaps the most interesting thing about these images is how similar they are to one another. There is standard language used to convey common ideas. Thus, the individual stories build on each other to reinforce a utopian college life, consciously or unconsciously, contradicting many of the more negative perceptions about higher education today.

\section{Note}

${ }^{1}$ There are an estimated 110.2 million television households in the US. A single ratings point represents 1 percent or 1 , 102,000 households for the 2005-2006 television season.

\section{References}

Abrams, J.J. and Reeves, M. (Executive Producers) (1998-2002), "Felicity", WB, Los Angeles.

Anderson, C. (1994), “'Dear Prospective Student' An analysis of admissions materials from four universities," College \& University, 70, 1, pp. 28-38.

BCS Bowl TV Ratings and Attendance (20032004), Retrieved June 30, 2004 from BCSfootball.org/ratings04.shtml.

Braxton, J.M., Vesper, N. and Hossler, D. (1995), "Expectations for college and student persistence," Research in Higher Education, 36, pp. 595-611.

Chu, J. (2005 March 14), "Fighting words 101,” Time, 185 , pp. 38-39.

Consoli, J. (2006, January 9), "Rose Bowl ratings up 59\%," Mediaweek, Retrieved February 14, 2006, from http//:www.mediaweek.com/mw/ news/networks/article_display.jsp?vnu_content_ id $=1001807317$.

Gerdes, H., \& Mallinckrodt, B. (1994 January/ February), Emotional, Social, and academic adjustment of college students, Journal of Counseling and Development, 72, 3, pp. 281-292.

Gitlin, T. (2000 December 8), "The renaissance of anti-intellectualism," The Chronicle of Higher Education, 47, pp. B7-B9.

Hite, R.E. and Yearwood, A. (2001), "A content analysis of college and university viewbooks (brochures)," College \& University, 76, 3, pp. 17-21.

Horn, L. and Berger, R. (forthcoming), "College Persistence on the Rise? Changes in 5-Year Degree Completion and Postsecondary Persistence Between 1994 and 2000 (NCES, 2004-156), table 5. Data from U.S. Department of Education, NCES, $1989 / 90$ and 1995/96 Beginning Postsecondary Students Longitudinal Studies (BPS:90/94 and BPS: 96/01)", Retrieved chart January 20, 2006 from http://nces. ed.gov/programs/coe/2004/section3/indicator 19 . asp\#info.

Jugenheimer, D.W. (1995), “Advertising the university: A professional approach to promoting the college or university," Journal of Marketing for Higher Education, 6, 1, pp. 1-22. 
Kittle, B. (2000), "Institutional advertising in higher education," Journal of Marketing for Higher Education, 9, 4, pp. 37-52.

Klassen, M.L. (2000), "Lots of fun, not much work, and no hassles: Marketing images of higher education," Journal Marketing for Higher Education, 10, 2, pp. 11-26.

Kuh, G.D. (1991, Winter), The role of admissions and orientation in creating expectations for college life, College and University, 66, pp. 75-82.

Kuh, G.D., Gonyea, R.M. and Williams, J.M. (2005), "What students expect from college and what they get," in T. E. Miller, B. E. Bender, J. H. Schuh, and Associates (eds.) Promoting Reasonable Expectation (pp. 34-64)s JosseyBass, San Francisco.

Reitman, I. and Simmons, M. (Producers) (1978), "National Lampoon's Animal House [Motion Picture]", Universal Pictures, United States.

Students and parents agree: Academics beats athletics (2004, July), Recruitment \& Retention in higher education, 18, pp. 1-2.

Terenzini, P.T., Springer, L, Yaeger, P.M., Pascarella, E.T. and Nora, A. (1996), "First-generation college students: Characteristics, experiences, and cognitive development," Research in Higher Education, 37, pp. 1-22.

Tobolowsky, B. (2001), "The influence of primetime television on Latinas' college aspirations and expectations", Unpublished doctoral dissertation, UCLA.

Toma, J.D. and Cross, M.E. (1998), "Intercollegiate athletics and student college choice: Exploring the impact of championship seasons on undergraduate applications," Research in Higher Education, 39, pp. 633-661.

Toma, J.D. (2003), "Football U: Spectator sports in the life of the American university", University of Michigan Press, Ann Arbor, MI.

2004-2005 Bowl Game Ratings, Retrieved Febuary 5, 2005 from www.bcsfoorball.org/index. $\mathrm{cfm}$ ? page $=$ tvratings.

Weimann, G. (2000), “Communicating unreality: Modern media and the reconstruction of reality," Sage Publications, Thousand Oaks, CA.

Whedon, J. (Executive Producer) (1999-2000), "Buffy: The Vampire Slayer", WB, Los Angeles. 